\title{
Caminhar, desacelerar - uma experiência com audiotour e fotoperformance na escola
}

\section{Walk, slow down - an experience with audiotour and photoperformance at school}

Paulina Maria Caon ${ }^{1}$

Getúlio Góis de Araújo ${ }^{2}$ 


\section{Resumo}

Este texto objetiva o compartilhamento reflexivo de experiências realizadas na disciplina "Estágio de Atuação/Interpretação em Espaços Escolares" e "Práticas Teatrais", do Curso de Teatro da Universidade Federal de Uberlândia em parceria com docente e estudantes da ESEBA, Escola de Educação Básica da UFU. O texto apresenta alguns procedimentos de trabalho propostos aos estudantes, em diálogo com práticas contemporâneas que utilizam o caminhar como ato estético, referenciando-se em criadores brasileiros e estrangeiros. Ao final, buscamos refletir sobre a relevância e o sentido de tais práticas contemporâneas no contexto da Educação Básica e da formação de professores.

Palavras-chave: Formação de professores; teatro em espaços escolares; práticas artísticas contemporâneas; caminhada como ato estético

\section{Abstract}

Este texto objetiva o compartilhamento reflexivo de experiências realizadas na disciplina "Estágio de Atuação/Interpretação em Espaços Escolares" e "Práticas Teatrais", do Curso de Teatro da Universidade Federal de Uberlândia em parceria com docente e estudantes da ESEBA, Escola de Educação Básica da UFU. O texto apresenta alguns procedimentos de trabalho propostos aos estudantes, em diálogo com práticas contemporâneas que utilizam o caminhar como ato estético, referenciando-se em criadores brasileiros e estrangeiros. Ao final, buscamos refletir sobre a relevância e o sentido de tais práticas contemporâneas no contexto da Educação Básica e da formação de professores.

Keywords: Teacher training; theater in school spaces; contemporary practices; walk as an aesthetic act

\footnotetext{
1 Profa. Dra. Universidade Federal de Uberlândia (UFU). Integrante de grupos de pesquisa no campo do Teatro e da Dança. Colabora com o Coletivo Teatro Dodecafônico desde 2008. paulinamariaus@yahoo.com

2 Prof. Dr. Escola de Educação Básica (ESEBA) - Universidade Federal de Uberlândia (UFU). Ator e pesquisador - getuliogois@gmail.com
} 


\section{Prólogo}

Caminhar é se dar a ocasião de estar na vertical de si mesmo [...] A solidão da caminhada é [...] uma liberação do inferno dos outros. Tentar se encontrar, pelo cuidado de si [...]. Ao longo de todo o dia, ao contrário, estamos atarefados, ocupados, preenchidos, saturados, invadidos [...]. Caminhamos então para encontrar nossa própria companhia [...]. (Gros apud Veloso, 2017, p.109)

A experiência que começamos a compartilhar nasce da vontade de desacelerar, caminhar a pé, olhar nos olhos e encontrar, corpo a corpo, com as diferenças: de idades, de experiências de vida, de trajetórias artísticas. Propondo-nos a partir desse encontro à gestação de outros modos de existência, ações minúsculas, singelas e singulares entrelaçando arte, estética, ética e micropolíticas num tempo de aceleração, esgotamentos e esvaziamento de significados em diferentes dimensões da vida social.

Esse texto tem a intenção de registrar e compartilhar a experiência singular de diálogo, invenção e ação conjunta entre dois docentes da UFU: um, professor de Teatro da Escola de Educação Básica da UFU (Eseba), outra, professora do Curso de Teatro da UFU.

Propusemos a coordenação conjunta dos componentes curriculares do Curso de Teatro "Estágio de Atuação/Interpretação em Espaços Escolares" (90h) e "Práticas Teatrais" (120h), colocando em contato e criação conjunta estudantes formandos do Curso de Teatro ${ }^{3}$ e estudantes de três turmas de nonos anos da Eseba.

Nossos encontros ocorriam duas vezes por semana na Eseba - uma delas no período das aulas de Teatro curriculares, com 50 minutos semanais, para as três turmas de nonos anos - e a segunda no contra turno escolar, apenas para estudantes interessados em participar das ações em horários extracurriculares. O terceiro encontro semanal acontecia no Bloco 3M, em que funciona o Curso de Teatro no campus Santa Mônica da UFU. O encontro no horário curricular, com o tempo, tornou-se o espaço para a síntese e socialização das experimentações em tempo ampliado feita nos horários extracurriculares. Ambas entrelaçaram-se na construção de um audiotour - faixa sonora que guia o percurso de um grupo de pessoas-espectadores-performers por certo espaço - e, mais ao final do semestre, na composição de fotoperformances - ações performáticas criadas com o intuito primeiro de dialogar com o suporte fotográfico.

A proposta feita por nós aos estudantes envolvia alguns elementos bastante específicos com o intuito de engendrar uma experiência coletiva de criação, nascida no contexto escolar por meio desse encontro entre docentes e discentes da UFU e da Eseba:

- Rodízio da coordenação dos encontros entre os professores, possibilitando que ambos estivéssemos em jogo junto aos estudantes em diferentes momentos do processo.

- Performance conjunta dos estudantes e docentes em suas diferentes idades e trajetórias artísticas.

\footnotetext{
3 Cinco estudantes da graduação viveram o processo dos componentes curriculares: Fernando Cardoso, Gustavo Bacci, Isaías Zuza Nascimento, Lucas Mali e Sara Valadão. Desde já manifestamos nossos agradecimentos à entrega dos mesmos ao processo e às trocas que estabelecemos nesse período de convivência. Do mesmo modo, agradecemos aos estudantes dos nonos anos da ESEBA que estiveram no processo nos horários curricular e/ou extracurricular.
} 
- Estudo conjunto de referências artísticas contemporâneas que utilizam a caminhada como prática estética.

- Experimentação de procedimentos criativos vinculados à caminhada - itinerâncias, errâncias, derivas -, bem como à composição de textos e imagens, resultantes dessas experiências de caminhada.

Além de instaurar outros tempos e espaços para o aprendizado e criação no contexto escolar (na graduação ou na Educação Básica), outro ponto de partida nos interessava particularmente no campo da formação de professores de Teatro: o encontro horizontal entre as diferentes experiências artísticas de adolescentes, jovens e adultos como modo de criar no contexto escolar. Em ocasiões anteriores esse componente curricular (Estágio Supervisionado de Atuação/Interpretação em Espaços Escolares) foi elaborado como uma montagem teatral, que, quando pronta, foi apresentada no espaço escolar. Nosso interesse foi viver experiências artísticas contemporâneas, imersos no espaço escolar, colocando esses corpos diversos, com suas trajetórias singulares em interação num processo que apostou na horizontalidade dessas relações.

Das ações que levaram ao audiotour:

- Silenciar, ralentar, caminhar ao lado, olhar nos olhos, levar passear;

- Mapas afetivos - caminhar pelos espaços escolares, deixando-se levar pelas memórias afetivas de sua trajetória nele - seguido de escrita automática sobre a experiência;

- A partir das escrituras, levantamos: espaços, ações, emoções;

- Improvisação a partir da relação corpo-arquitetura nos espaços preferidos dos estudantes e em outros espaços da escola;

- Improvisação a partir da relação movimento-som com fragmentos dos textos escritos por eles;

- Organização do roteiro, articulando seleções de textos, itinerância pelos espaços preferidos, trilha sonora selecionada coletivamente;

- Gravação de audiotour e testes do percurso;

- Realização do audiotour com a própria turma;

Nesse sentido, a proposta dialoga com Rancière (2002), quando afirma a igualdade de inteligências como ponto de partida para o encontro pedagógico. Tal igualdade não é compreendida como o apagar as diferenças e assimetrias entre os participantes, mas busca aproveitar as tensões, a diversidade de qualidades de movimento, imagens, textos, nascida das diferentes maneiras de viver as proposições pelos participantes. Por fim, ao longo do processo, não se tratava de chegar a uma produção final para ser apresentada, mas gerar cotidianamente ações performáticas, algumas mais outras menos efêmeras, que interferissem de algum modo no cotidiano escolar (Eseba e UFU). 


\section{Primeiro fluxo - as caminhadas para o audiotour}

El caminar es una apertura al mundo. Restituye en el hombre el feliz sentimiento de su existencia. Lo sumerge en una forma activa de meditación que requiere una sensorialidad plena. [...] La facultad propiamente humana de dar sentido al mundo, de moverse en él comprendiéndolo y compartiéndolo con los otros, nació cuando el animal humano, hace millones de años, se puso en pie. La virtualización y integración del andar bípedo favorecieron la liberación de las manos y de la cara. La disponibilidad de miles de movimientos nuevos amplió hasta el infinito la capacidad de comunicación y el margen de maniobra del hombre con su entorno, y contribuyó al desarrollo del cerebro. La especie humana comienza por los pies, nos dice Leroi-Gourhan, aunque la mayoría de nuestros contemporáneos lo olvide y piense que el hombre desciende simplemente del automóvil. (Le Breton, 2002, p.15 e 16)

$\mathrm{Na}$ construção do audiotour, propusemos uma sequência de procedimentos de trabalho, que envolveram desde o conhecimento de algumas referências artísticas (Denise Pereira Rachel, Janet Cardiff, Projeto Caracol, Rimini Protokoll, os situacionistas), a deriva pelo espaço escolar a partir das memórias sensoriais dos estudantes, passando pela escrita automática após a errância por tais espaços, até a experimentação da ocupação corporal de recortes espaciais da arquitetura escolar presentes nos escritos dos estudantes. Os textos resultantes de tais escritas automáticas foram lidos pelo grupo de participantes dos horários extracurriculares, com foco no levantamento das emoções, espaços, ações recorrentes, bem como na seleção de fragmentos dessas textualidades que contribuíram na construção do roteiro para a faixa sonora do audiotour. Propomos a seguir um pequeno mergulho em fragmentos desse roteiro, com o intuito de aproximar os leitores da experiência sensorial proposta.

Viramos à esquerda e caminhamos até a portaria da Educação Infantil, percorrendo esse longo corredor.

Ao final desta música você poderá ver o céu. Caminhe no ritmo dela (Música 3 Se essa rua fosse minha - Domínio Público - Arranjo Rafael Cortez)

O que há depois das grades coloridas?

2 - Atravessamos a grade e passamos para fora (Música 4 - Palhaço - Egberto Gismonti). Observe esse espaço e aproxime-se da grade colorida à direita, de onde se enxerga os parquinhos. O que você vê? Onde sua criança brincava? Quais memórias te atravessam...?

A escola que eu passei a minha infância. Entrando. Saindo. Indo e vindo. Vou sentir saudades de tudo. A árvore, os bancos, grades, as cores...

Pegue novamente na mão de sua criança e a leve de volta até a entrada do corredor. Dê a vocês um tempo. Ainda não caminhe.

Agora sim, caminhe novamente pelo corredor, com atenção. (trilha sonora aumenta o volume) Observe cada porta aberta, cada sala no caminho...

Nesta escola fiz e desfiz amizades, ri, chorei.

Nesta escola tive meus primeiros; primeiro contato com tantas pessoas, primeiro beijo, primeiro melhor amigo. Qual foi sua primeira sala de aula, sua primeira professora? 
Eu perdido, eu chorando, eu abraçando, eu não sabendo, eu feliz, eu no recreio, eu no banheiro, eu correndo, eu e outros, eu e poucos, eu querendo fugir, eu descobrindo, eu com medo, eu na primeira vez...

3 - Atenção. Passe pela tia Edna e vá até a sala do dentista.

Entre devagar, encontre um lugar diante do espelho e pare um pouco (Música 5 - La Valse des Monstres - Yann Tiersen). Se observe no espelho. Sorria. Quanto você tem de se abaixar para enxergar seu rosto no espelho? Lembra de quando você precisava ficar na ponta dos pés? Quanto você cresceu?

Lembra do que sentia quando chamavam o seu nome para vir aqui? Hora de arrancar um dente de leite... hora de descobrir se estava com cáries ou não, de passar flúor e fazer boca roxa. Lembra de cuspir a boca roxa nessa pia? A partir de onde estão, formem uma fila e caminhem tranquilamente em direção à ducha. Em um minuto se vive um ano. É só atravessar o corredor... a despedida... para perceber o que fica e o que vai.

Os lugares, assim como as pessoas, também mudam.

Siga as flechas do chão e o piso de bolinhas até entrar na ducha. $[\ldots]$

(Vozes sobrepostas e aceleradas)

Oi, tchau, tudo bom, de novo, velho, feio, legal, chato, feio, bonito, rir, chorar, ai, Irineu não sabe... nem eu, hotwheels, backyardigans, liga da justiça, star wars, som, ir, vir, ver, gostar, odiar, bola, bolo, frango pai, mãe, irmão, irmã, querer, poder, saber, tola, mentir, filho, sobrinho, neto, Janaína, Michel, Douglas, Juliano, Washington, Miami, estar na Disney, Orlando, Best buy, aula, escola, professor, cheirando cola, boom, bomba, terrorismo, buginganga, livro, house, uber, crise, family, car, calça, fome, brócolis, alface, caju, manga, família, presente, tudo, frio, calor, sono, poder, justiça, corrupção, vida, asfalto, chegar, gargalhar, cama, dormir, vida, presente, obrigado, nada, morrer. [...]

7 - Chegamos na porta de vidro. Pausa. Respire. (Portaria com porta fechada) Quando a música começar, caminharemos em câmera lenta em direção à calçada, em direção ao mundo de fora. (Música 12 - Au fond de bois - Pierre Van Dormael) Coragem! É hora da despedida...

Atenção: olhe para trás e veja seu passado, sinta a transferência de peso de seus pés e a importância do pé de trás para que se possa caminhar para frente. Olhe para frente, a porta de saída que se abre, um futuro desconhecido...

Damos um passo e saímos para a calçada.

Viramos à esquerda e caminhamos nela. (Música 13 - Viva la Vida - Coldplay - apenas música por um tempo). Chegamos ao fim de nossa jornada juntos. Olhamos em volta e vemos nossos companheiros e companheiras de viagem. Olhe nos olhos, sorria se tiver vontade... Abrace se tiver vontade... Obrigada por termos dividido esse momento.

Agora é hora de dizer adeus. (Excertos do roteiro do audiotour)

Como buscamos deixar claro na transcrição desses fragmentos, o texto foi composto por diferentes naturezas textuais e sonoras. Os trechos em negrito são oriundos das escritas automáticas de todos os participantes do processo, o restante foi composto pelos docentes e estudantes da graduação para a orientação espacial e manutenção de um fio narrativo (a relação com as memórias dos estudantes ESEBA e a criança de cada futuro ouvinte da faixa sonora). A trilha sonora (em itálico e entre parênteses no fragmento) foi escolhida em conjunto pelos participantes do horário 
extracurricular. Além disso, durante o percurso caminhado do audiotour, algumas ações eram performadas no espaço (na primeira vez, pelos estudantes da graduação, e na segunda vez, pelos próprios estudantes da Educação Básica), fruto da experimentação anterior com os recortes espaciais.

Na vivência do processo, percebemos o desafio da gravação da faixa sonora para todos nós, seja pelo tempo de trabalho planejado para a composição do audiotour, seja porque nenhum de nós havia tido oportunidade de trabalhar efetivamente dentro de um estúdio de gravação em processos anteriores. Como preparação vocal para as gravações em estúdio, realizamos experimentos apoiados em procedimentos de trabalho de Koudela (2001), na abordagem de textos como material sonoro, e na apropriação lúdica de fragmentos textuais de Pupo (2005). Estas abordagens foram escolhidas por proporcionar uma exploração ampla e lúdica com a voz, descartando preciosismos técnicos relacionados ao universo do áudio. Interessava-nos ainda que todos pudéssemos nos apropriar dos diversos sentidos e possibilidades sonoras do roteiro que nascia antes de passar para a gravação propriamente dita.

A Eseba conta com um pequeno estúdio de gravação utilizado em projetos de rádio na escola. Lá foram gravadas as leituras que seriam utilizadas na composição do audiotour. Esta etapa foi repleta de descobertas e combinados em vários níveis. Tecnicamente, o silêncio do estúdio e a captação refinada do microfone, desvelaram qualidades e sutilezas da fala de cada um dos envolvidos. De outro lado, essas características do espaço exigiram de nós uma atitude mais formal, diferente daquela que vinha sendo experimentada no cotidiano das aulas. Após cada gravação era possível apreciar o áudio e conjuntamente era discutido o que poderia ser aperfeiçoado. Não é comum escutarmos a própria voz gravada e esse momento trouxe à tona os interesses e também as dificuldades pessoais de todos em relação a esse aspecto do processo (a voz gravada, a exploração de poéticas vocais). Nossa estratégia, para não expormos tais dificuldades pessoais e aproveitar o tempo de reserva do local, foi gravar várias versões de certos fragmentos do roteiro, com diferentes vozes. Assim foi possível optar pelas sonoridades mais interessantes para cada trecho no momento da edição, cuja versão final tem vozes dos professores, graduandos e estudantes da Educação Básica.

Como docentes, ao avaliar o processo, concluímos que um audiotour traz tantas diferentes demandas e oportunidades de aprendizado em sua composição que poderia ocupar um semestre ou um ano inteiro de trabalho. A dimensão sonora desde a experimentação vocal até a gravação e edição da faixa sonora - poderia ser ainda mais experimentada se tivéssemos maior tempo de trabalho.

O audiotour finalizado foi experimentado por todas as turmas de nonos anos que participaram do processo em junho de 2017, bem como por participantes do I Seminário Regional de Educação Básica: ensino - pesquisa - políticas públicas, em outubro de 2017. Ao final do ano, durante a 4‥ Mostra de Arte da Eseba, o audiotour foi apresentado como trabalho final dos nonos anos para a outra metade da turma que cursava Artes Visuais ${ }^{4}$.

$4 \mathrm{Na}$ área de Artes da Eseba, as turmas são divididas ao meio, podendo experimentar num semestre uma modalidade artística e no semestre seguinte outra. Assim, a metade da turma que estava fazendo Teatro pôde propor a experiência do audiotour ao final do ano com a metade da turma que estava fazendo Artes Visuais com outra docente da escola. 
Estes momentos de partilha estética da experiência com o audiotour, potencializado pelo fato das turmas de nonos anos estarem finalizando sua trajetória escolar dentro da Eseba, foi vivenciado com muita emoção. Tanto estudantes quanto alguns docentes que puderam realizá-lo, afirmaram sua potência como proposta de ressignificação do espaço e das memórias da vida escolar que amplia as possibilidades de elaboração e atribuição de sentido às experiências individuais e coletivas dos participantes.

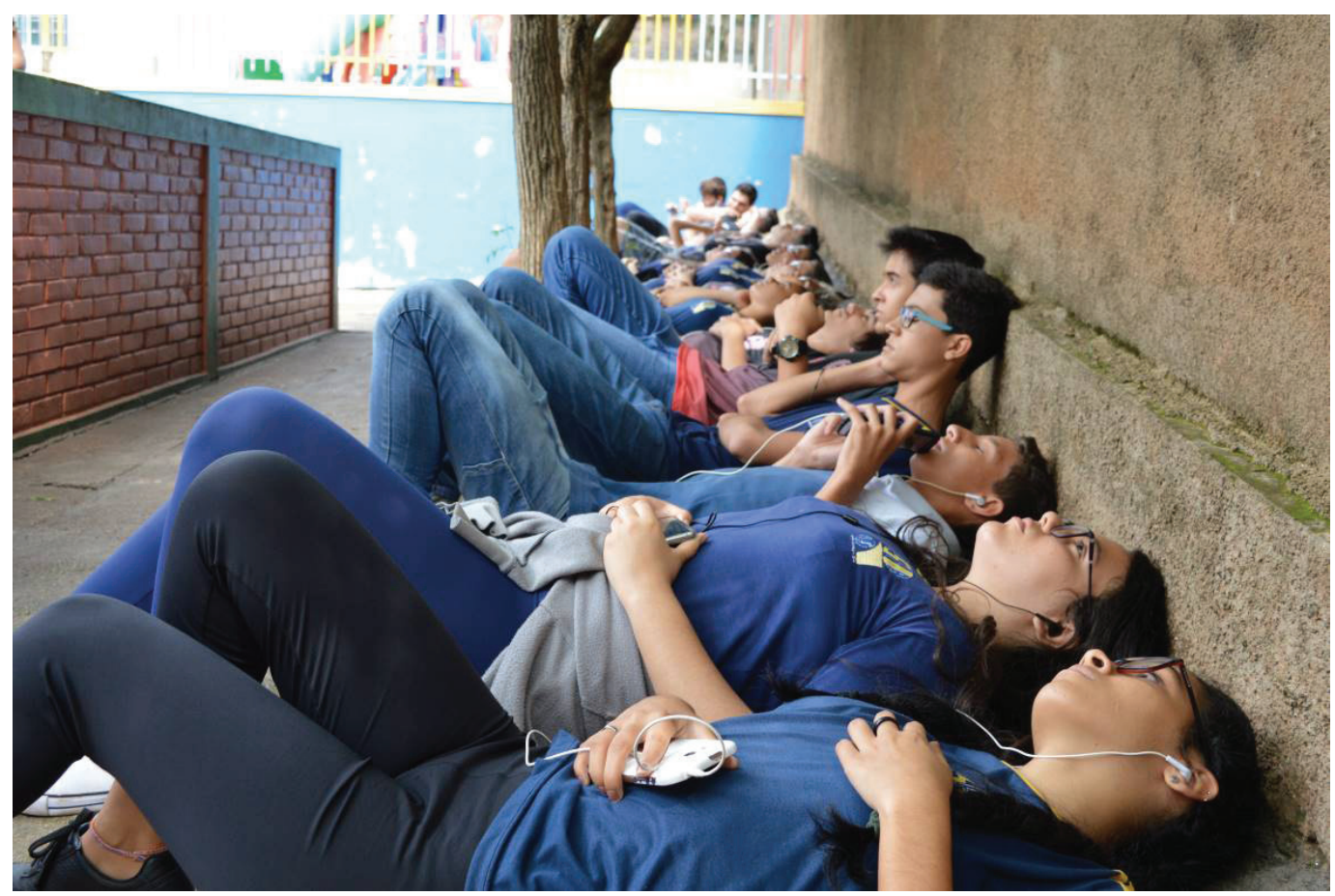

Figura 1 - Apresentação final de audiotour durante a $4^{\circ}$. Semana de Arte da Eseba Fonte: arquivo pessoal

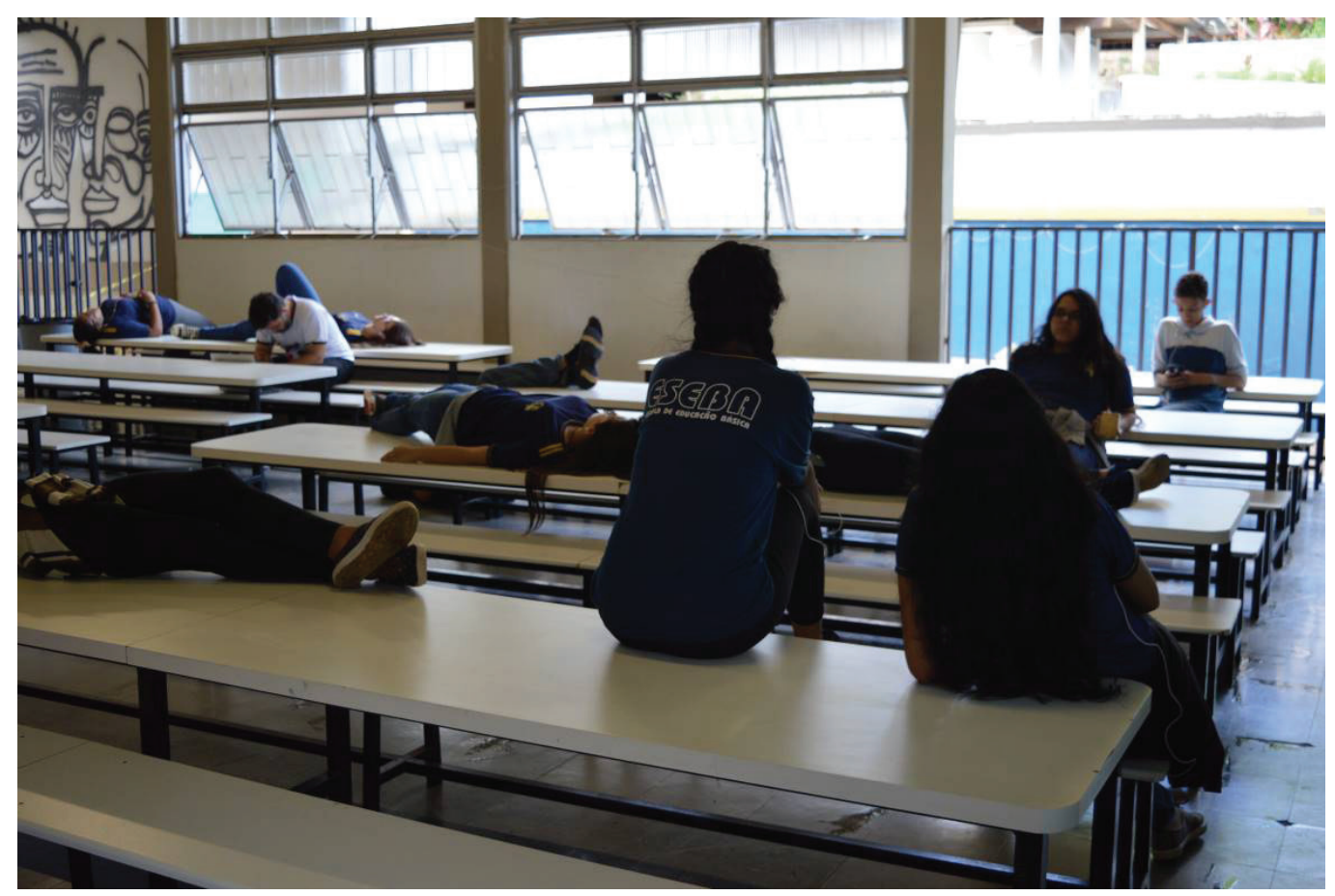

Figura 2 - Performers compondo imagens nas mesas e bancos do refeitório da escola Fonte: arquivo pessoal 


\section{Segundo fluxo - as ações da fotoperformance}

Em nosso planejamento, as relações corpo-arquitetura/espaço urbano, corpo-objetos previa a fruição e realização de fotoperformances. A introdução desse eixo temático foi subsidiada pela apresentação de referências artísticas internacionais, nacionais e locais: Cindy Sherman, Coletivo Teatro Dodecafônico, Francesca Woodman, Mariana Guerrón, Morena Nascimento, Rodrigo Braga, Valie Export. Que o momento da fruição, bem como o debate das imagens e vídeos não soe como algo contemplativo e por isso destituído de conflito. Ao contrário, os diferentes períodos de aproximação com as referências artísticas provocaram muitas inquietações entre os adolescentes, principalmente em relação ao sentido das obras. Um exemplo claro dessas inquietações diz respeito às obras de Rodrigo Braga. Dentre as várias relações de seleção, repetição e contato corporal com objetos e animais, Braga manipula digitalmente fotos e cria, em Fantasia de compensação, uma sequência de imagens em que o artista simula uma cirurgia plástica de simbiose entre a cabeça de um cachorro e seu próprio rosto. O debate acalorado sobre ética na arte, levantado pelo fato da cabeça de cachorro ser "real" foi acirrado entre alguns estudantes, sendo necessário desvelar detalhes dos procedimentos legais da produção do artista.

Aquecidos e instigados, experimentamos estar no espaço relacionando-nos com objetos variados, previamente selecionados. Como vínhamos trabalhando até ali, a proposição estava pautada em pressupostos muitos simples: de um lado, na interrupção do tempo acelerado no encontro corporal com o ambiente e a materialidade desses objetos; de outro, na abertura sensorial para deixar-se estar com eles, agir com eles, encaixar-se, misturar-se, mover-se neles/com eles. Os estudantes da graduação, como já vinha ocorrendo, se revezaram na experimentação da proposta e realização das fotos. Tal exercício possibilitou que eles ampliassem a discussão sobre os sentidos intencionais ou emergentes das imagens, dialogando uns com os outros sobre suas percepções diante das proposições dos próprios colegas da graduação ou da escola básica. De certo modo, toda essa etapa também foi um aquecimento estético (Ott apud Barbosa, 1999) para o modo como trabalharíamos na composição das fotoperformances.

Para a realização da proposta de fotoperformances de cada um dos estudantes, dividimos cada sala em subgrupos, ficando cada graduando responsável pelo processo e registro de um subgrupo por sala, seguindo as seguintes etapas:

1- Orientação e agendamento em subgrupos para composição do projeto de fotoperformance de cada estudante do nono ano: diálogo entre graduandos e estudantes da Eseba a respeito de desejos, lugares e objetos escolhidos, a fim de cada estudante definir qual ação, composição visual/corporal desejada e o local na escola em que gostaria de ser fotografado.

\footnotetext{
5 Analogia ao sistema de trabalho proposto por Robert William Ott em processos de ensino de crítica de arte em museus. Trata-se dos procedimentos de percepção sensorial, de jogo, de apreciação estética que precedem e/ou aquecem para a criação, em nosso caso, das fotoperformances, e, no caso de Ott, da própria crítica de obras de arte.
} 
2- Realização de projetos de maneira simultânea: cada graduando registrava seu estudo fotográfico a partir do diálogo e interação com o estudante agendado para aquele dia/horário. Os demais estudantes do mesmo subgrupo acompanhavam e auxiliavam na realização dos trabalhos dos colegas, tendo a oportunidade de apreciar e debater o processo de cada um.

3- Seleção, edição e apresentação de propostas de imagens finalizadas aos graduandos e estudantes da escola básica. Tal seleção foi feita com os participantes do horário extracurricular, visto que cada sessão de fotos com um estudante chegou a gerar mais de cem imagens, por exemplo.

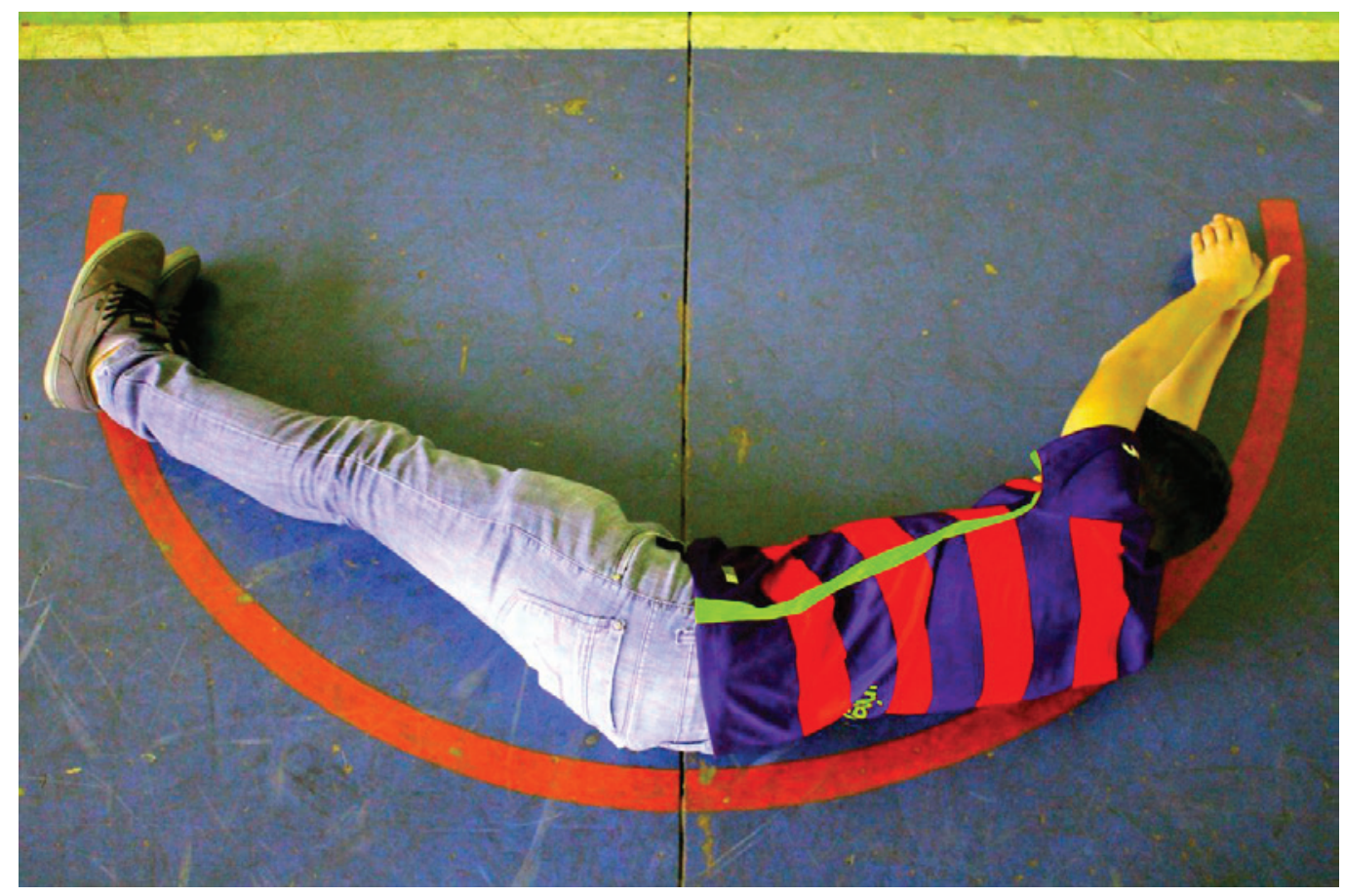

Figura 3 - Fotoperformance de estudante da Eseba. Fonte: arquivo pessoal

A foto acima, uma das 40 fotoperformances realizadas no segundo fluxo, é resultado desse diálogo entre o estudante da Educação Básica e um graduando. Nela, a composição evidencia o jogo corporal com a linha de marcação do piso da quadra esportiva da escola. As cores da linha vermelha e do piso azul, intensificadas no processo de edição de imagem, dialogam com a camiseta do aluno e com obras de Valie Export, artista austríaca apresentada aos estudantes, que em 1976 criou uma série intitulada Body Configurations, na qual o corpo dela interage com estruturas arquitetônicas de diversos espaços urbanos, acentuados pela intervenção de linhas pretas e vermelhas na foto já realizada. 


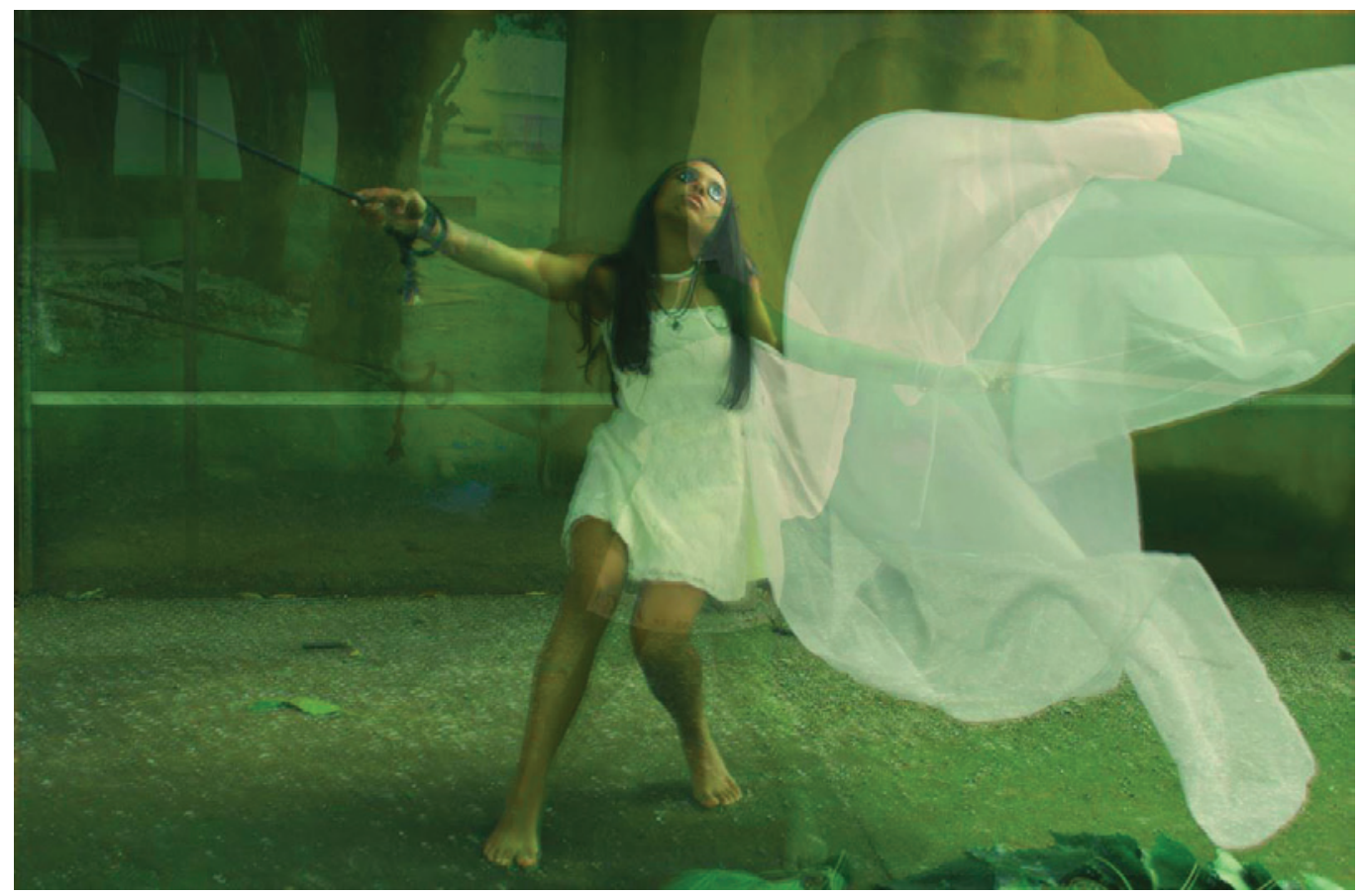

Figura 4 - Foto performance de estudante da Eseba. Fonte: arquivo pessoal

Na figura 4, a estudante dialoga nitidamente com outro referencial apresentado durante as aulas, imagens da artista Morena Nascimento. A estudante, instigada pela fluidez dos tecidos e ilusão de movimento na obra da artista, escolhe para trabalhar o mesmo elemento (tecido), que é arremessado várias vezes para o alto. Amarrada pelos dois braços e com olhos fechados por botões grandes de camisa (que nos parece referência direta à animação Coraline), o efeito desejado pela estudante somente foi alcançado com a edição da imagem.

Em nossa avaliação, mesmo que a relação com os equipamentos tenha se dado tecnicamente em nível básico, a investigação e troca de saberes entre todos proporcionou resultados significativos nas imagens e também no despertar de interesses de estudantes específicos em relação à criação com fotografia. As fotoperformances foram apresentadas em exposição dentro da programação de encerramento do I Semestre do Curso de Teatro e na 4‥ Semana de Arte da Eseba.

\section{Dizendo Adeus}

O universo evocativo da criação e experiência do audiotour, em suas camadas sensoriais do encontro corpo-espaço, corpo-palavras-e-sonoridades, potencializam o ato de caminhar pelo espaço escolar, proporcionando aos participantes uma imersão multissensorial e afetiva neste espaço. Nessa experiência de concha acústica (pelos fones de ouvido) os participantes, jovens e adultos, estão mergulhados em si, na faixa sonora e nas ações que são convidados a realizar nesse outro tempo-espaço instaurado. Revisitam memórias e recriam sentidos para seu cotidiano escolar, por vezes embotado pela urgência dos dias.

A criação das fotoperformances trouxe à tona singularidades, desejos e temas individuais, surpreendentes para todos, envolvendo desde a relação mais direta com o desempenho escolar, até a vida mais subjetiva e o universo ficcional de interesse dos estudantes. A complexidade da vida na juventude e a potência estética das pro- 
postas feitas emergiram, fazendo-nos questionar afirmações generalizantes sobre a alienação ou o desinteresse subjetivo, político, artístico dos mesmos.

Assim, certas práticas no universo da arte contemporânea, tantas vezes tidas como herméticas e complexas, aqui potencializaram a aproximação dos estudantes com a experiência artística. Eles foram não apenas fruidores capazes de interagir sensivelmente com as referências apresentadas no cotidiano, mas também propositores de debates e ações artísticas instigantes sobre a vida na atualidade.

O ato de caminhar, a observação do espaço por outras perspectivas, a permissão sutil de deixar-se sensível aos estímulos, colocam esta proposta em diálogo como o tema da dissolução da obra de arte enquanto espetáculo, evidenciando aspectos éticos e estéticos que nos colocam no campo do mergulho e da reinvenção de modos de existência do ser humano.

Como experiência estreitamente vinculada à formação de professores de Teatro, a proposta como um todo e a escolha desse universo estético questionam as supostas limitações (espaciais, temporais, institucionais) da escola para o acolhimento do fazer teatral. Mais ainda, parece-nos que a experiência aponta para a relevância da abordagem de uma cena em campo expandido (Caballero, 2011) nesse componente curricular, seja na universidade, seja na escola. $O$ borramento de fronteiras entre as artes e a imbricação entre vida subjetiva, vida social e ação artística são alguns dos traços que caracterizam essa abordagem e potencializam sua existência no contexto escolar.

\section{Referências}

CABALLERO, Ileana Diéguez. Cenários Liminares: teatralidades, performances e política. Uberlândia: EDUFU, 2011.

KOUDELA, Ingrid Dormien. Brecht na pós-modernidade. São Paulo: Perspectiva, 2001.

LE BRETON, David. Elogio del Caminar. Barcelona: Ediciones Siruela, 2002.

PUPO, Maria Lúcia de Souza Barros. Entre o Mediterrâneo e o Atlântico. São Paulo: Perspectiva, 2005.

OTT, Robert William. Ensinando crítica nos museus. In: BARBOSA, Ana Mae. Arte-Educação: leitura no subsolo. SP: Cortez, 1999, p.113-141.

RANCIĖRE, Jacques. O Mestre-ignorante: cinco lições sobre emancipação intelectual. BH: Autêntica, 2002.

VELOSO, Verônica Gonçalves. Percorrer a cidade a pé. São Paulo, 2017. Tese (Doutorado) - Escola de Comunicações e Artes da Universidade de São Paulo. 